\title{
Article \\ Dual-Band, Dual-Output Power Amplifier Using Simplified Three-Port, Frequency-Dividing Matching Network
}

\author{
Xiaopan Chen, Yongle Wu *(D) and Weimin Wang
}

check for

updates

Citation: Chen, X.; Wu, Y.; Wang, W. Dual-Band, Dual-Output Power Amplifier Using Simplified Three-Port, Frequency-Dividing Matching Network. Electronics 2022, 11, 144. https://doi.org/10.3390/ electronics11010144

Academic Editors: Leonardo Pantoli, Egidio Ragonese, Paris Kitsos and Gaetano Palumbo

Received: 6 December 2021 Accepted: 30 December 2021 Published: 4 January 2022

Publisher's Note: MDPI stays neutral with regard to jurisdictional claims in published maps and institutional affiliations.

Copyright: (C) 2022 by the authors. Licensee MDPI, Basel, Switzerland. This article is an open access article distributed under the terms and conditions of the Creative Commons Attribution (CC BY) license (https:// creativecommons.org/licenses/by/ $4.0 /)$.

\author{
School of Electronic Engineering, Beijing University of Posts and Telecommunications, Beijing 100876, China; \\ chenxiaopan@bupt.edu.cn (X.C.); wangwm@bupt.edu.cn (W.W.) \\ * Correspondence: wuyongle138@gmail.com
}

\begin{abstract}
This study presents a dual-band power amplifier (PA) with two output ports using a simplified three-port, frequency-dividing matching network. The dual-band, dual-output PA could amplify a dual-band signal with one transistor, and the diplexer-like output matching network (OMN) divided the two bands into different output ports. A structure consisting of a $\lambda / 4$ open stub and a $\lambda / 4$ transmission line was applied to restrain undesired signals, which made each branch equivalent to an open circuit at another frequency. A three-stub design reduced the complexity of the OMN Second-order harmonic impedances were tuned for better efficiency. The PA was designed with a 10-W gallium nitride high electron mobility transistor (GaN HEMT). It achieved a drain efficiency (DE) of $55.84 \%$ and $53.77 \%$, with the corresponding output power of 40.22 and $40.77 \mathrm{dBm}$ at 3.5 and $5.0 \mathrm{GHz}$, respectively. The $40 \%$-DE bandwidths were over $200 \mathrm{MHz}$ in the two bands.
\end{abstract}

Keywords: dual-band; dual-output; gallium nitride (GaN); harmonic control; power amplifier (PA); restraining network

\section{Introduction}

With the development of wireless communication systems, people have been seeking methods for higher data rates. It is essential to increase spectral efficiency because spectrum resources are limited. As a result, the research on RF transmitters that can operate on multiple bands has attracted more attention. Power amplifiers (PAs) are necessary parts of RF transmitters. Therefore, one of the research trends focuses on how to design PAs that can operate over multiple frequencies, such as multiband [1-7], broadband [8-12], and band-tunable PAs [13]. Existing studies have achieved multiband operation in different conditions. For example, Refs. [1,2] present dual-band and quad-band PAs in MMIC using on-chip impedance transformers, and Refs. [3-5] implemented a dual-band characteristic within a Doherty PA structure. Some studies investigated different ways of matching multiband impedance. Dai et al. [6] explored a direct solving method for triband matching networks. Meng et al. [7] reported a synthesis method that could create dual-band impedance rotation to increase the bandwidth and gain flatness of PAs.

Carrier aggregation (CA) and multiple-input multiple-output (MIMO) are important technologies to improve spectral efficiency. CA utilizes different bands within the available spectrum, whether they are contiguous, noncontiguous, or broadly separated. MIMO multiplies transmission and receiving antennas, which may work on different carrier frequencies for better radiation pattern performance [14,15]. In carrier aggregation MIMO front ends, multiple PAs are needed to feed every antenna element on its working frequency, which causes higher costs.

A new type of multiband PA that has multiple output ports was presented recently [16]. A dual-band, dual-output PA was designed for the dual-band case. It could perform as a dual-array feed network with its diplexer-like output matching network (OMN) [17]. It worked like a general dual-band PA that could amplify a dual-band signal with one 
transistor. The difference is that it could separate the signal into two single-band signals and send them into two different output ports by its OMN. The architecture of the PA is shown in Figure 1. It had a power-added efficiency (PAE) of 40.4\%/39.9\% and an output power of 36.7/37.1 dBm at 3.5/5.5 GHz. The methodology used in Ref. [16] to achieve the specially featured OMN was an iterative process of tuning, and no harmonic termination was conducted in the design, which limited its efficiency. Therefore, the design simplicity and performance of the original work need to be further improved.

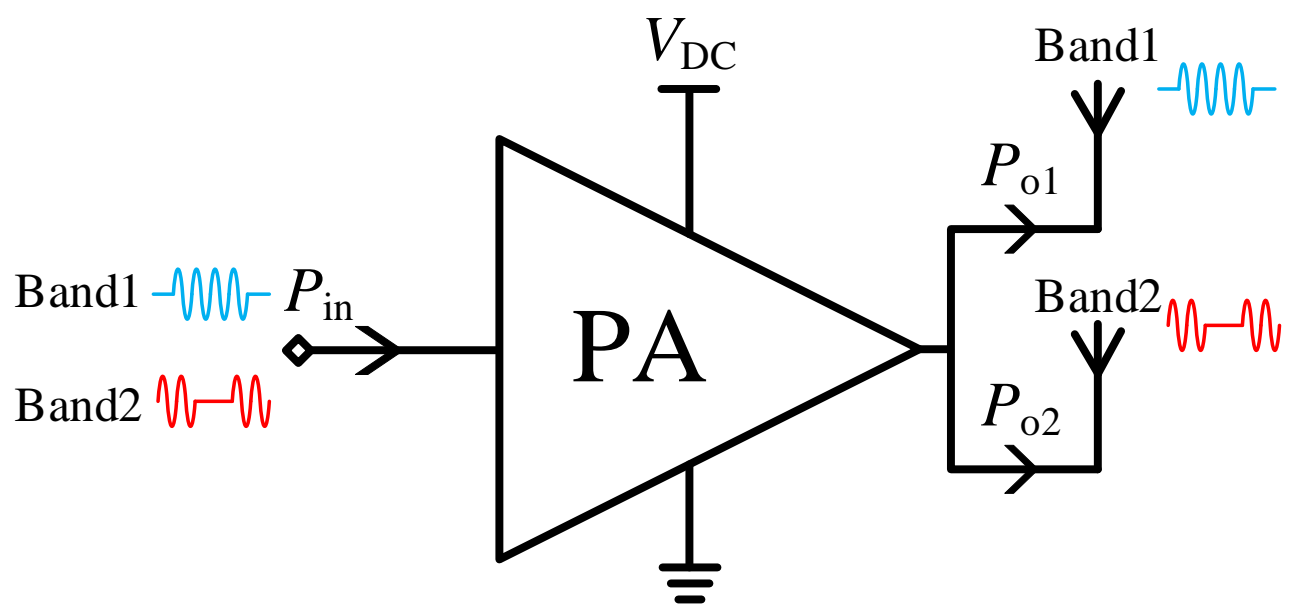

Figure 1. Block diagram of the dual-band, dual-output PA presented in Ref. [16].

This study presents a newly designed dual-band, dual-output PA with a detailed matching procedure and a generalized design methodology. The output matching uses a simplified three-port, frequency-dividing matching network to miniaturize the circuit and reduce its complexity. A structure consisting of a $\lambda / 4$ open stub and a $\lambda / 4$ transmission line was applied to prevent the signal from passing through improperly. Second-order harmonic impedances were tuned for better efficiency. A 10-W gallium nitride high electron mobility transistor (GaN HEMT) was used to deliver more power. Finally, the newly designed PA achieved a drain efficiency (DE) of $55.84 \% / 53.77 \%$ and output power of $40.22 / 40.77 \mathrm{dBm}$ at 3.5/5.0 GHz. Moreover, the two branches could create stopband rejections of more than $24.4 \mathrm{~dB}$ at $3.5 \mathrm{GHz}$ and $38.6 \mathrm{~dB}$ at $5 \mathrm{GHz}$.

\section{Design Methodology}

\subsection{Restraining Network}

The two branches in the frequency-dividing matching network were required to prevent signals in the other band from passing through. The restraining network shown in Figure 2 was applied for that purpose. It consisted of an open-circuit stub and a transmission line.

The open-circuit stub with the characteristic impedance $Z_{2}$ and the electrical length $\theta_{2}$ was used to create a short-circuit condition for minimizing the influence of the OMN with the input impedance $Z_{\text {in1 }}$ when they were connected in parallel. The transmission line with the characteristic impedance $Z_{1}$ and the electrical length $\theta_{1}$ transferred the short-circuit condition to an open-circuit condition.

As shown in Figure 2, the input impedance of the branch with the restraining network can be written as:

$$
Z_{\text {in }}=Z_{1} \frac{Z_{\text {in } 2}+j Z_{1} \tan \theta_{1}}{Z_{1}+j Z_{\text {in } 2} \tan \theta_{1}}
$$

where

$$
Z_{\text {in } 2}=\frac{Z_{\text {ino }} Z_{\text {in } 1}}{Z_{\text {ino }}+Z_{\text {in } 1}}
$$


The input impedance of the open-circuit stub was determined by

$$
Z_{\text {ino }}=\frac{-j Z_{2}}{\tan \theta_{2}}
$$

Combining Equations (1)-(3), $Z_{\text {in }}$ can be calculated as

$$
Z_{\text {in }}=Z_{1} \frac{-j Z_{2} Z_{\text {in } 1}+j Z_{1} Z_{\text {in } 1} \tan \theta_{1} \tan \theta_{2}+Z_{1} Z_{2} \tan \theta_{1}}{Z_{2} Z_{\text {in } 1} \tan \theta_{1}+Z_{1} Z_{\text {in } 1} \tan \theta_{2}-j Z_{1} Z_{2}}
$$

When $\theta_{2}=90^{\circ}$, the effect of $Z_{\mathrm{in} 1}$ on $Z_{\text {in }}$ vanishes. Moreover, if $\theta_{1}=90^{\circ}$, the restraining network will make the branch behave as an open circuit.

$$
\begin{gathered}
Z_{\text {in }}\left(\theta_{2}=90^{\circ}\right)=j Z_{1} \tan \theta_{1} \\
Z_{\text {in }}\left(\theta_{2}=90^{\circ}, \theta_{1}=90^{\circ}\right)=\infty
\end{gathered}
$$

In the branch of $f_{1}$, lengths of the open-circuit stub and the transmission line were set as $\lambda / 4$ at $f_{2}$. Then the branch will be equivalent to an open circuit at $f_{2}$. At the same time, $\mathrm{Z}_{\text {in }}$ at $f_{1}$ will be

$$
\begin{aligned}
& \left.Z_{\text {in }}\right|_{f=f_{1}, \theta_{1}=\theta_{2}=90^{\circ} @ f_{2}} \\
& =Z_{1} \frac{-j Z_{2} Z_{\text {in } 1}+j Z_{1} Z_{\text {in } 1} \tan ^{2}\left(\frac{\pi f_{1}}{2 f_{2}}\right)+Z_{1} Z_{2} \tan \left(\frac{\pi f_{1}}{2 f_{2}}\right)}{Z_{2} Z_{\text {in } 1} \tan \left(\frac{\pi f_{1}}{2 f_{2}}\right)+Z_{1} Z_{\text {in } 1} \tan \left(\frac{\pi f_{1}}{2 f_{2}}\right)-j Z_{1} Z_{2}}
\end{aligned}
$$

By setting a proper OMN after the restraining network, $Z_{\text {in }}$ could be tuned to the optimal impedance of the transistor.

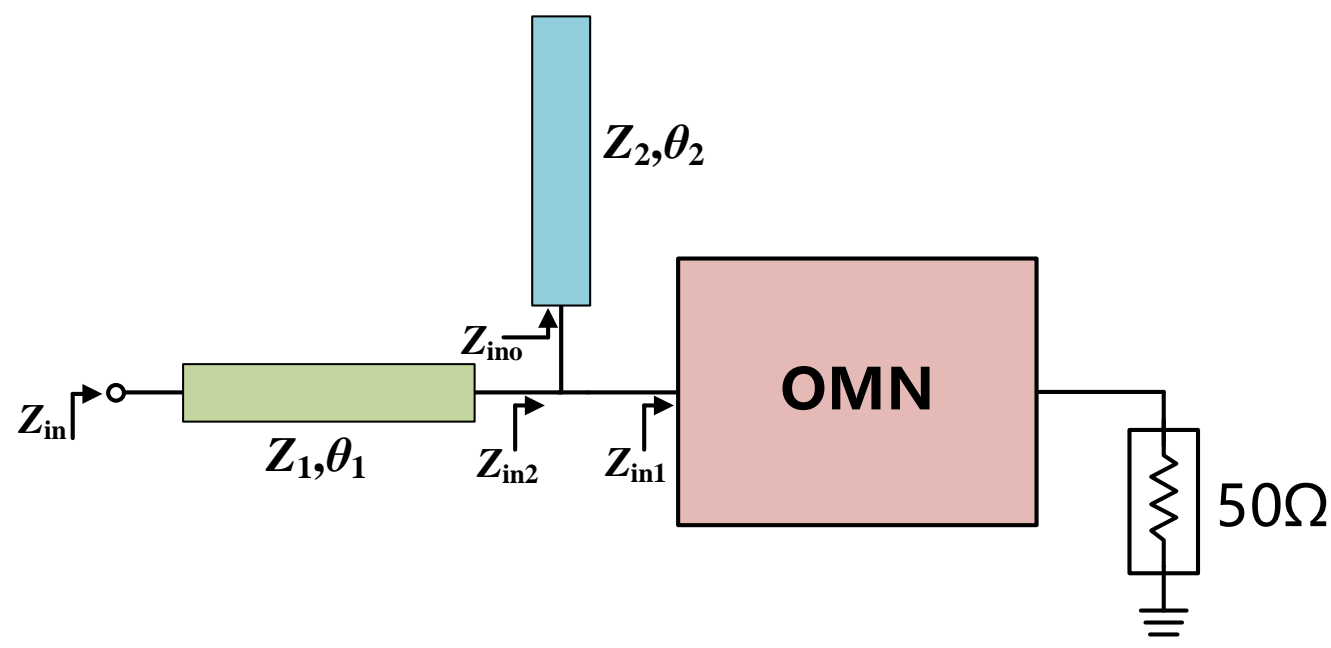

Figure 2. Circuit model of the proposed restraining network.

\subsection{Design of Output Matching Network}

For higher efficiency and output power, a Cree Wolfspeed 10 W CGH40010F (CREE, Durham, NC, USA) packaged GaN HEMT was used for the design. The two operating frequencies were $3.5 \mathrm{GHz}\left(f_{1}\right)$ and $5.0 \mathrm{GHz}\left(f_{2}\right)$ near the widely used sub-6 GHz $5 \mathrm{G}$ bands.

The first step of designing the three-port, frequency-dividing output matching network was finding the optimal impedance for the transistor. Using the nonlinear transistor model provided by the manufacturer, the simulated load-pull results at fundamental, secondorder, and third-order harmonic frequencies are presented in Figure 3. Contours were taken at the package plane of the transistor. Under consideration of output power and PAE, the targeted input impedances of OMN were chosen near $12 \Omega$ at $f_{1}$ and $10 \Omega$ at $f_{2}$. 


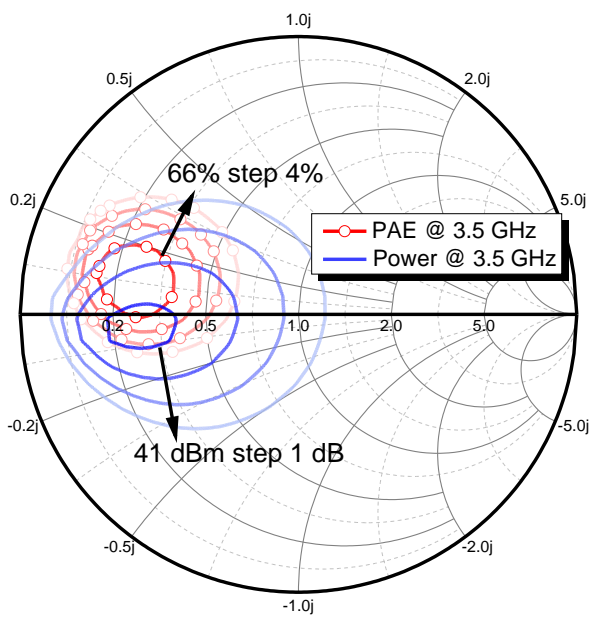

(a)

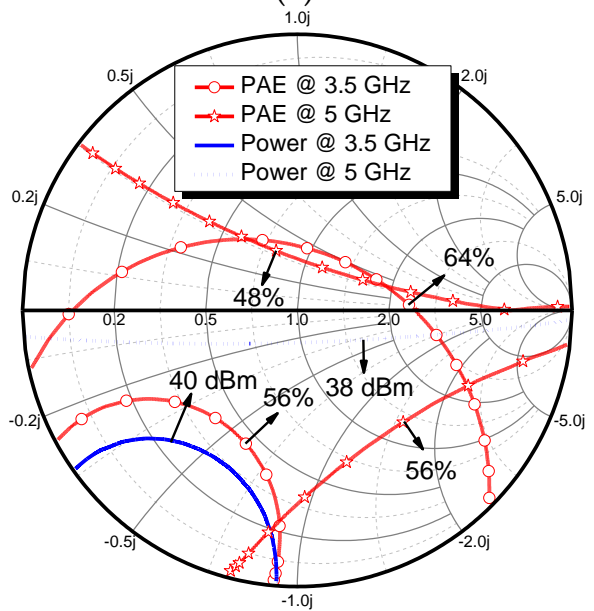

(c)

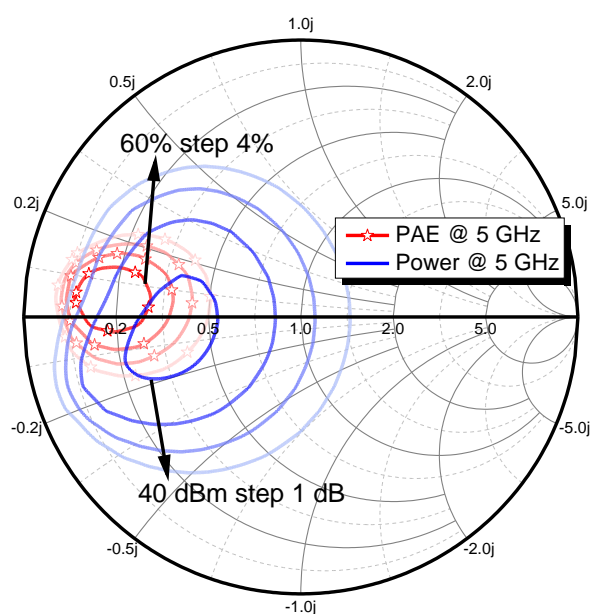

(b)

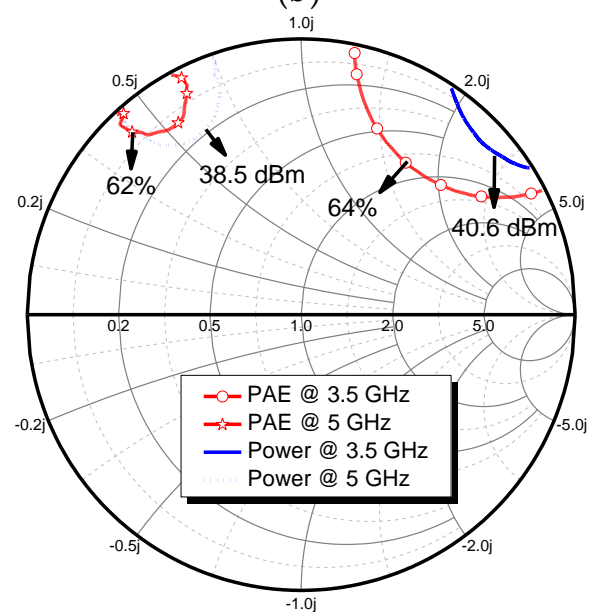

(d)

Figure 3. Simulated load-pull results at (a) the fundamental frequency of $f_{1},(\mathbf{b})$ the fundamental frequency of $f_{2}$, (c) second-order harmonic frequencies, and (d) third-order harmonic frequencies.

The topology of the dual-band, dual-output PA is schematically shown in Figure 4. The two branches of the OMN had the optimal impedance to the transistor at its working frequency. Simultaneously, it behaved as an open circuit at another frequency, which prevented the branch from affecting the impedance at that frequency and guaranteed that signals in the other band would not interfere with its output. The restraining networks (TL $\mathrm{T}_{911}$ and $\mathrm{TL}_{10,12}$ ) were applied for this condition.

For better efficiency, harmonic tuning networks were employed after the restraining networks. Results in Figure 3c,d show that the second-order harmonic impedances positively influenced the performance. In contrast, the impact of the third-order harmonic impedances was much lower. Therefore, second-order harmonic impedance was tuned by this network, which means the proposed PA works in the class-J mode.

In the harmonic tuning network, a $\lambda / 8$ open stub $\left(\mathrm{TL}_{15}\right.$ and $\left.\mathrm{TL}_{16}\right)$ was used to create a short-circuited condition at the second-order harmonic frequency for the connecting point. Furthermore, the tuning line $\left(\mathrm{TL}_{13}\right.$ and $\left.\mathrm{TL}_{14}\right)$ tuned the condition at the package plane to be the proper impedance with the restraining network. 


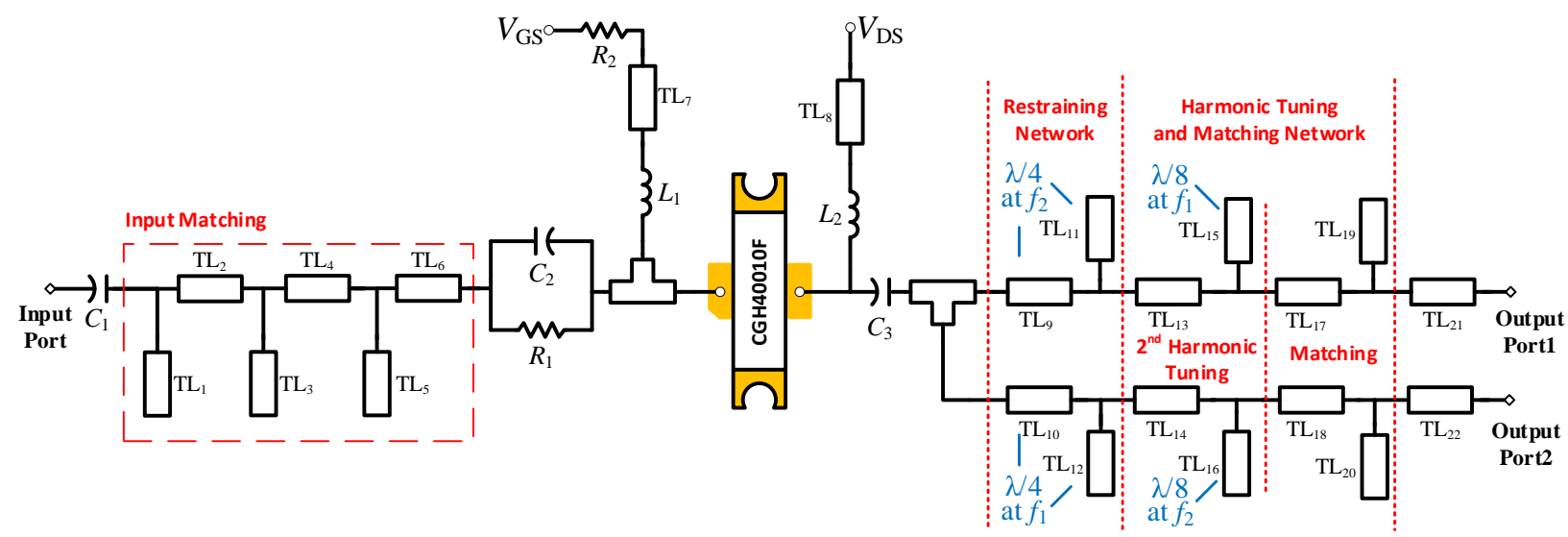

Figure 4. Block diagram of the harmonically tuned dual-band, dual-output PA. Output port1 output signals at $f_{1}=3.5 \mathrm{GHz}$. Output port 2 output signals at $f_{2}=5.0 \mathrm{GHz} . C_{1}=20 \mathrm{pF}, C_{3}=20 \mathrm{pF}, C_{2}=3 \mathrm{pF}$, $R_{1}=\mathrm{R} 2=50 \Omega, L_{1}=18 \mathrm{nH}, L_{2}=1 \mathrm{uH}$.

Stub-tuned matching networks ( $\mathrm{TL}_{17,19}$ and $\left.\mathrm{TL}_{18,20}\right)$ were applied after the harmonic tuning networks to make each branch match the optimal impedance of its operating frequency. The two branches were connected to make the three-port OMN. The restraining networks eliminated the interaction between the two branches at fundamental frequencies. However, the harmonic impedances may be influenced. Moreover, the blocking capacitor $\left(C_{3}\right)$, RF choke $\left(L_{2}\right)$, and soldering pad also affected impedances, so optimization was needed after the connection. Figure 5a depicts the input impedances of each branch after optimization, and Figure $5 \mathrm{~b}$ shows the input impedances of the three-port OMN, which were well matched to the region of high performance. All the impedances were simulated with the external components and circuits. The results imply that the fundamental impedances were near the point before the connection. However, the second-order and third-order harmonic impedances are changed at different degrees.

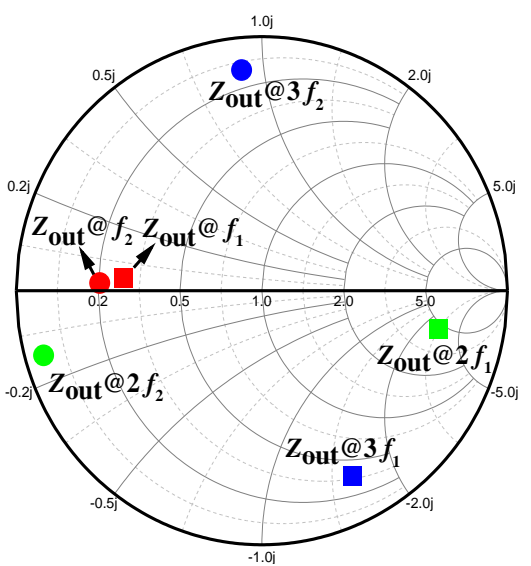

(a)

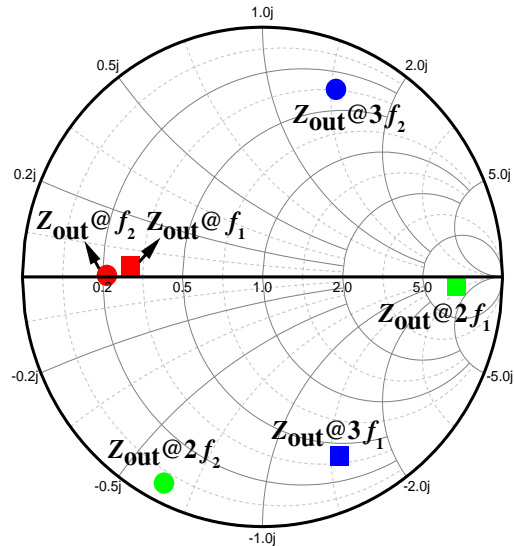

(b)

Figure 5. Input impedances of the two branches (a) before connected and (b) after connected.

The two branches were bent forward to reduce the size of the dual-output power amplifier and to balance the performance. The layout of the designed three-port, frequencydividing OMN is shown in Figure 6a. The three-stub branches lowered the complexity compared to the design in Ref. [16]. S-parameters of the three-port OMN are depicted in Figure $6 \mathrm{~b}$. The restraining networks created isolation of more than $40 \mathrm{~dB}$ between different bands, which ensured the high performance of the PA in working bands. Furthermore, the output ports isolation was also better than $40 \mathrm{~dB}$ near the working frequency. 


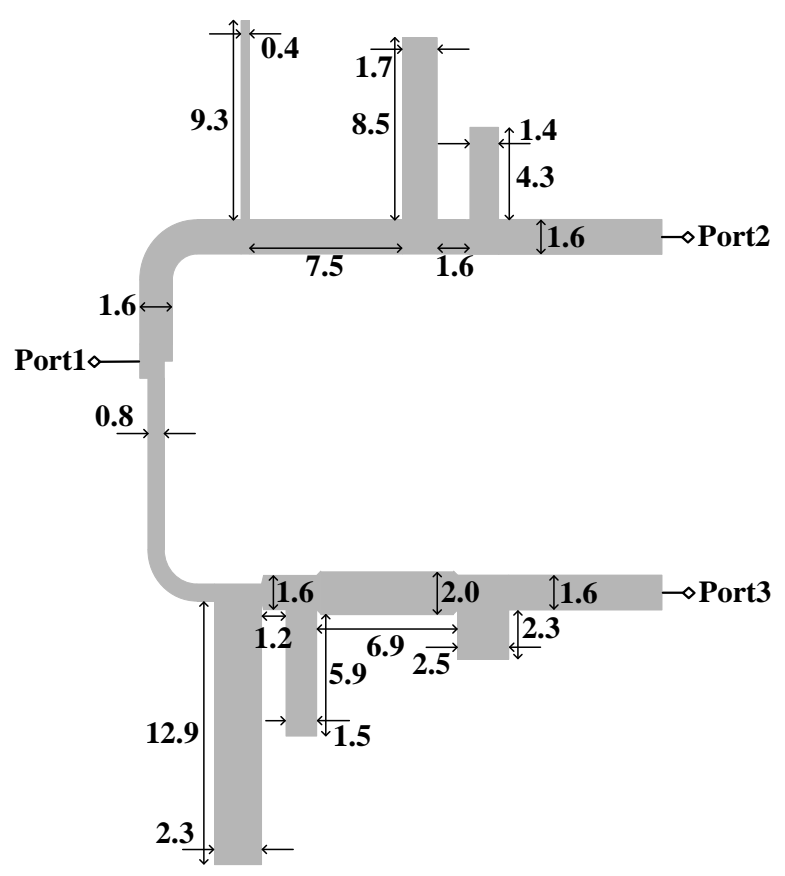

(a)
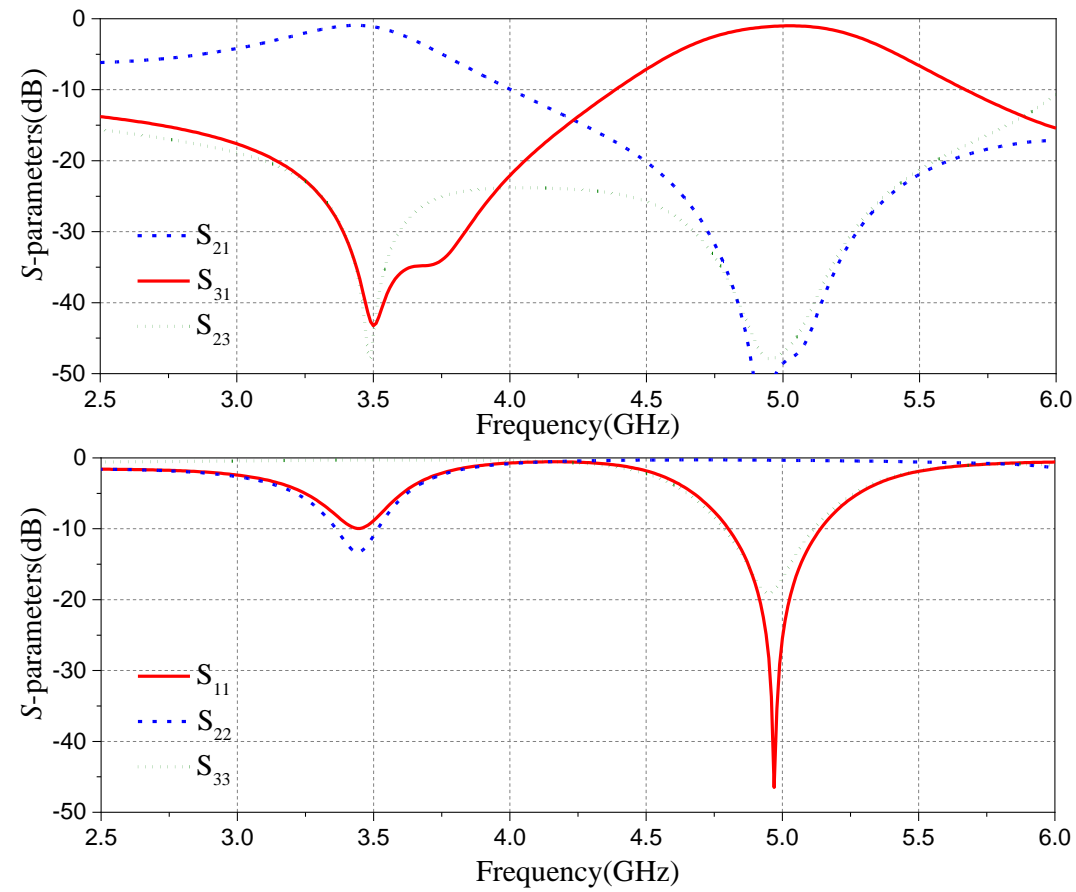

(b)

Figure 6. (a) Layout of the simplified three-port, frequency-dividing OMN with its main physical dimensions (unit: $\mathrm{mm}$ ) and (b) simulated $S$-parameters.

\subsection{Design of Input Matching Network}

Unlike the three-port OMN, the input matching network was a traditional dual-band matching network. Figure 7a shows the layout of it. The design of the input network refers to the dual-band matching technology based on compact broadband matching networks presented in Ref. [7]. The input network consisted of three open stubs and three transmission lines. Three stubs and two connecting lines $\left(\mathrm{TL}_{1}-\mathrm{TL}_{5}\right)$ created a dual-band impedance rotation. The rest line $\left(\mathrm{TL}_{6}\right)$ made the impedance move to the proper position. 


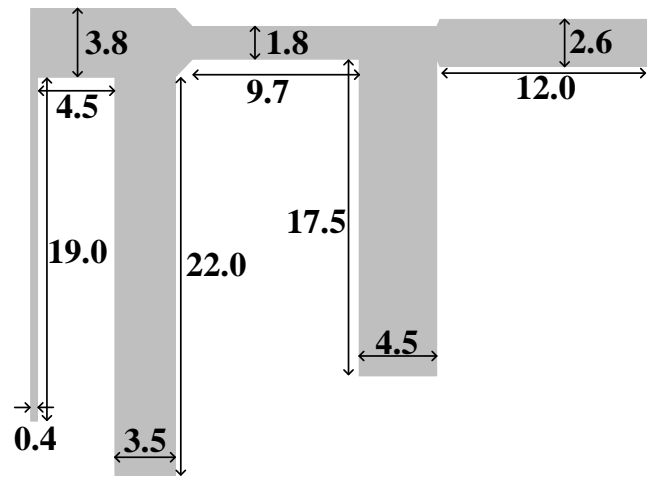

(a)

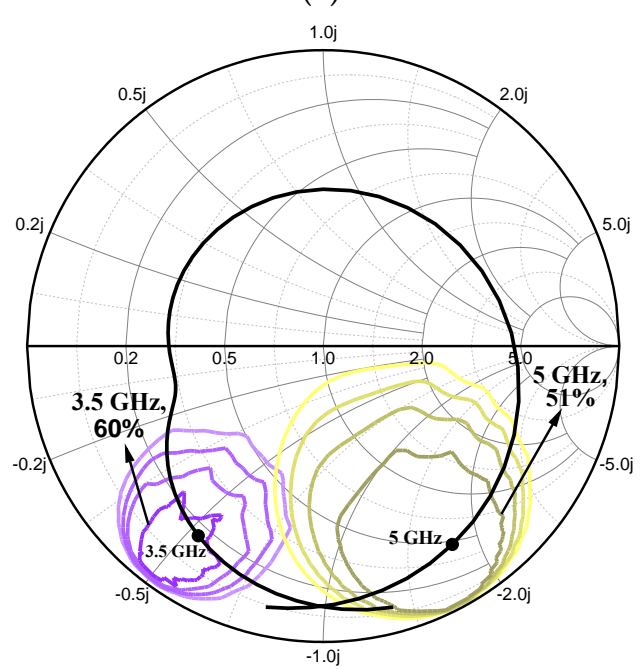

(b)

Figure 7. (a) Layout of the dual-band input matching network with its main physical dimensions (unit: $\mathrm{mm}$ ) and (b) the impedances of the input matching network from 3.2 to $5.2 \mathrm{GHz}$ with simulated source-pull contours of PAE (with $2 \%$ step) at $f_{1} / f_{2}$.

For stabilization, a parallel RC circuit $\left(C_{2}\right.$ and $\left.R_{1}\right)$ at the gate and a resistor $\left(R_{2}\right)$ before the gate bias line were added. After iterative optimizations, the network had the optimal impedance for the transistor in the working bands, and the stability factor satisfied the unconditionally stable requirement in the whole frequency range. Figure $7 \mathrm{~b}$ depicts the impedances of the input matching network from 3.2 to $5.2 \mathrm{GHz}$ with simulated source-pull contours of PAE at $f_{1} / f_{2}$.

\section{Fabrication and Measurement}

The proposed dual-band, dual-output PA shown in Figure 8a was performed on a 30-mil Rogers RO4350B (Rogers, Chandler, AZ, USA) substrate with a relative permittivity of 3.66 and a loss tangent of 0.0037, using a 10-W Cree CGH40010F GaN HEMT (CREE, Durham, NC, USA). The OMN was loaded with a 4310LC wideband RF choke. The transistor was biased and stabilized at a drain-source voltage $\left(V_{\mathrm{DS}}\right)$ of $28 \mathrm{~V}$, and the quiescent drain current $\left(I_{\mathrm{DS}}\right)$ was $168 \mathrm{~mA}$, which was selected in the class-AB region. The lumped-element capacitors used for blocking and stabilizing were Murata GRM18 series chip multilayer ceramic capacitors. 


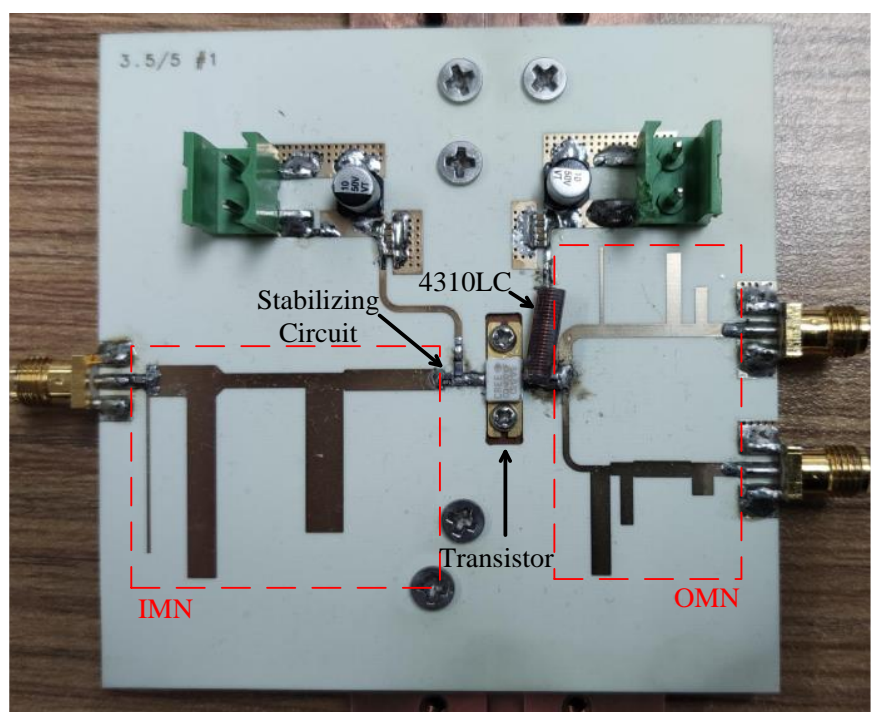

(a)
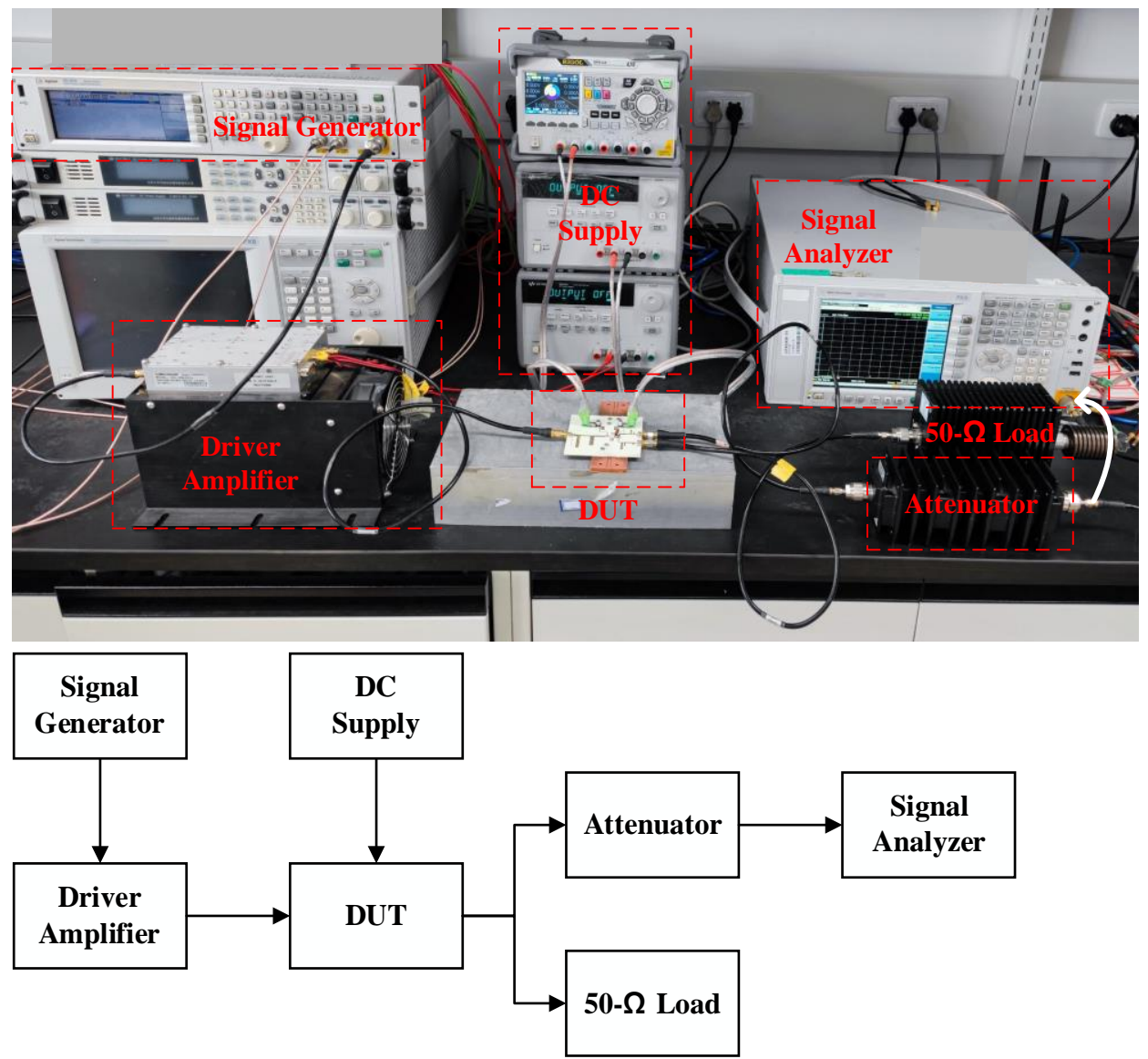

(b)

Figure 8. Photographs of (a) the fabricated 3.5/5.0 GHz dual-band, dual-output PA and (b) the measurement setup.

Figure $8 \mathrm{~b}$ demonstrates the test environment for the designed PA. An Agilent N5182A vector signal generator (Agilent, Santa Clara, NC, USA) was used to provide a CW signal. The signal was pre-amplified by a driver amplifier, since the output power of the generator was not enough to drive the PA. The output of the PA was measured by an Agilent N9030A signal analyzer (Agilent, Santa Clara, NC, USA). A 40-dB attenuator was added between the output port of the PA and the signal analyzer to prevent the large signal from exceeding 
the input limit of the analyzer. When one port is being measured, another should be connected to a $50-\Omega$ load to accord with practice.

The measured gain, output power, and DE of the proposed PA at $f_{1}$ and $f_{2}$ are depicted in Figure 9. At $3.5 \mathrm{GHz}$, the DE reached $55.84 \%$ when $P_{\text {in }}=31.7 \mathrm{dBm}$, with an output power of $40.2 \mathrm{dBm}$, and the small-signal gain was $11.6 \mathrm{~dB}$. At $5.0 \mathrm{GHz}$, the DE reached $53.77 \%$ when $P_{\text {in }}=33 \mathrm{dBm}$, with an output power of $40.7 \mathrm{dBm}$, and the small-signal gain was $9.8 \mathrm{~dB}$. Figure 10 gives the gain of the two output ports at the undesired frequencies. The stopband rejections of the two branches were better than $24.4 \mathrm{~dB}$ at $3.5 \mathrm{GHz}$ and $38.6 \mathrm{~dB}$ at $5 \mathrm{GHz}$.

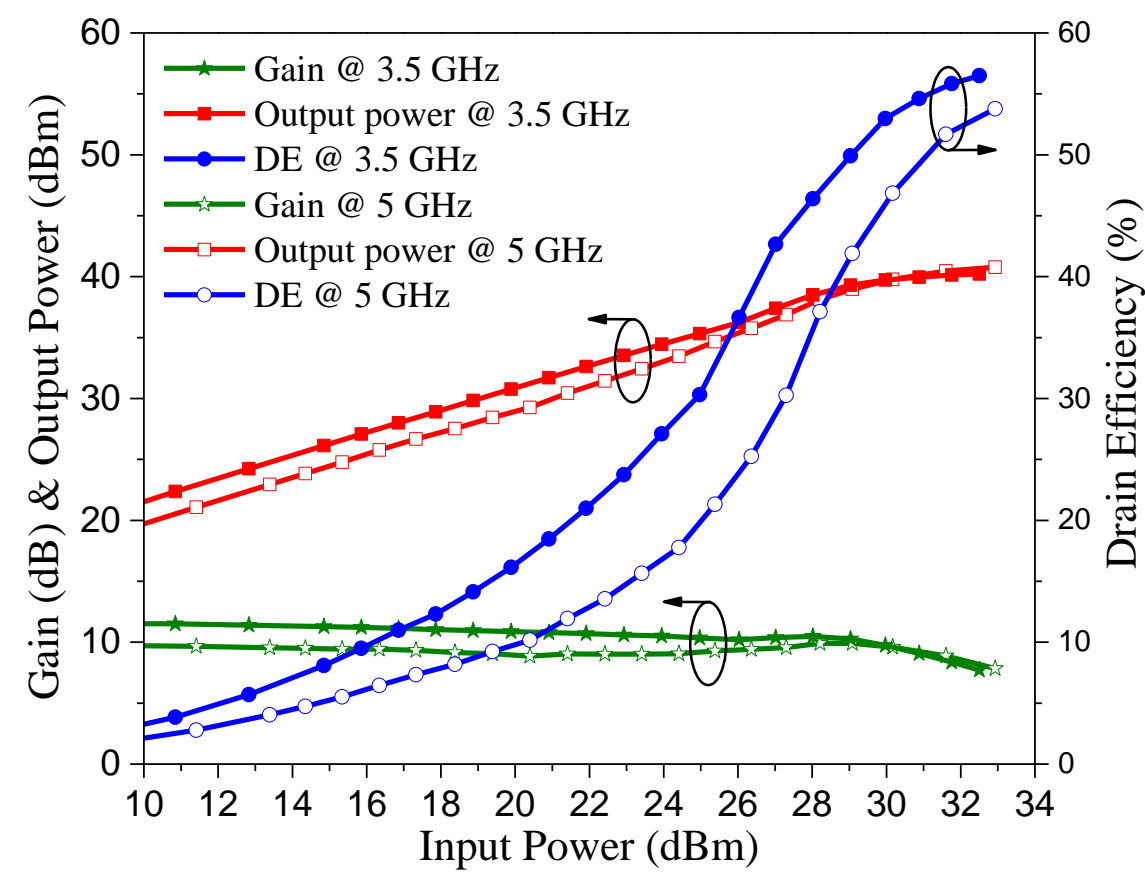

Figure 9. Measured gain, output power, and DE of the fabricated PA versus input power at $3.5 \mathrm{GHz}$ and $5.0 \mathrm{GHz}$, respectively.

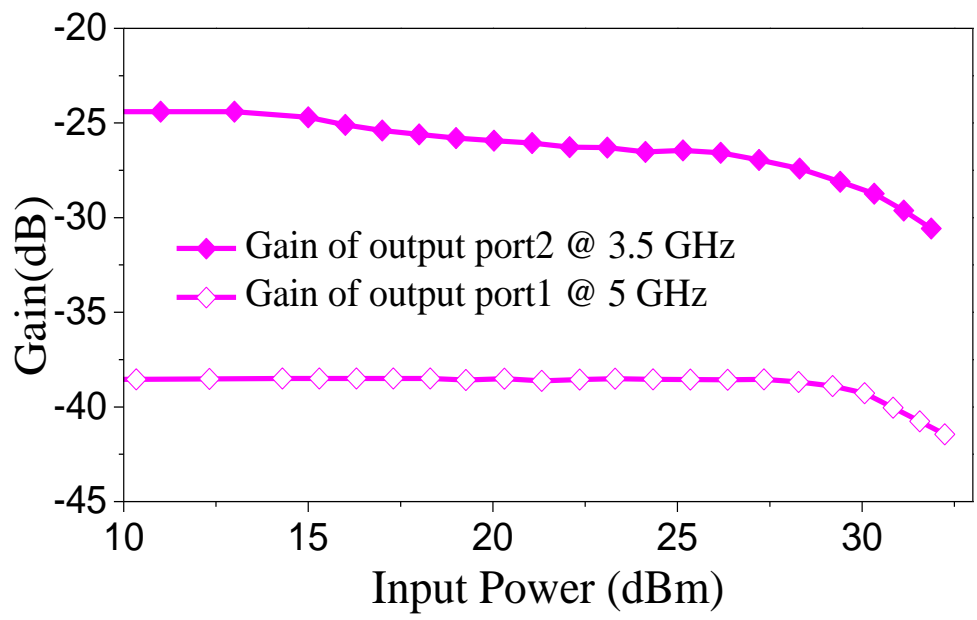

Figure 10. Measured gain of the two output ports at the undesired frequencies.

Figure 11 shows the performance over the two bands. The PA had a bandwidth of $200 \mathrm{MHz}$ over $40 \%$ efficiency near 3.5 and $5 \mathrm{GHz}$. The measured efficiency was lower than simulated results in the lower band. There were slight frequency shifts in both bands, which may have been caused by the impact of manufacturing variations and device deviation. The 
conductor width tolerance of the manufacturer was $0.02 \mathrm{~mm}$, and the amplitude accuracy of the signal analyzer was $\pm 0.19 \mathrm{~dB}$. It is found in experiments that the curvature of the circuit board can affect the performance. Therefore, more advanced manufacturing and better auxiliary accessories are needed for better performance.
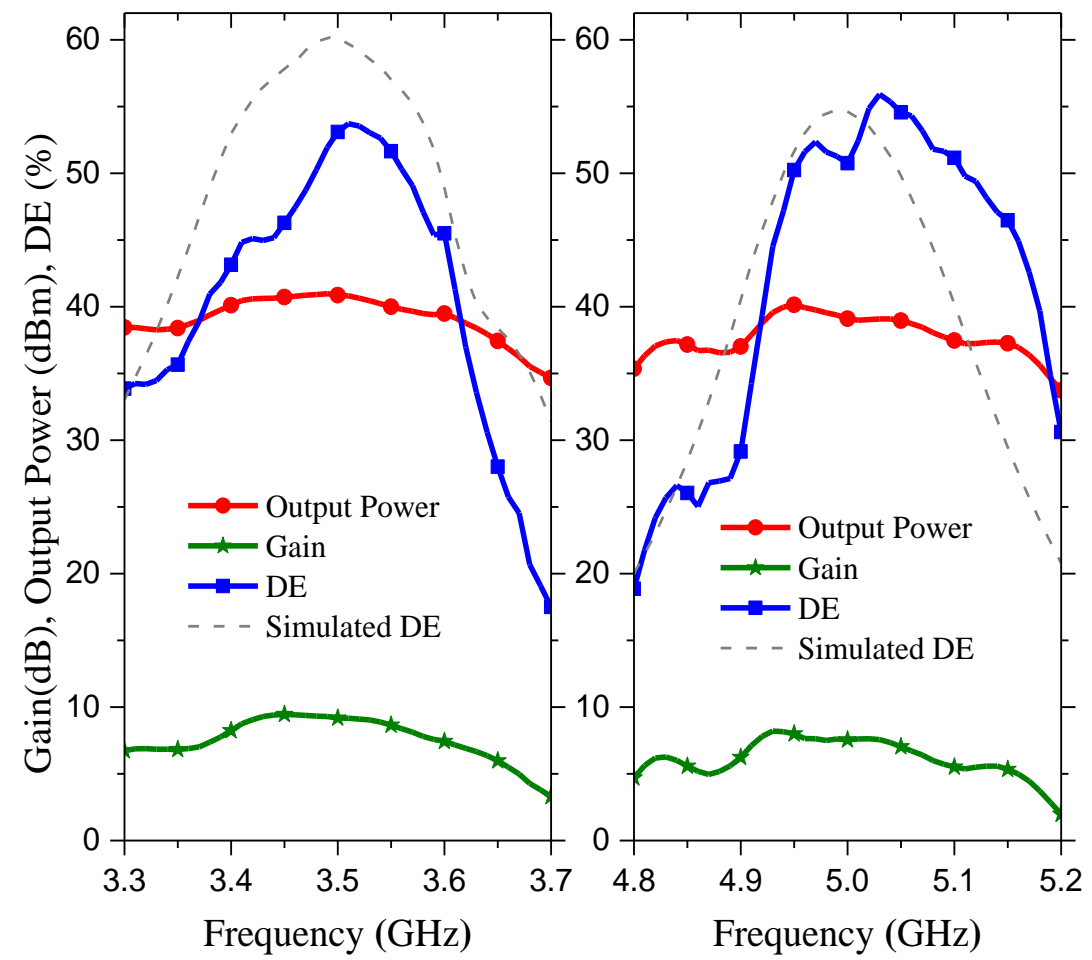

Figure 11. Measured gain, output power, and DE of the fabricated PA versus frequency over the two bands $\left(P_{\text {in }}=31 \mathrm{dBm}\right.$ near $f_{1}$ and $32 \mathrm{dBm}$ near $\left.f_{2}\right)$.

To evaluate the linearity, the proposed PA was tested with a 10-MHz WCDMA signal with a peak-to-average power ratio (PAPR) of $6.6 \mathrm{~dB}$. Figure 12 shows the measured normalized power spectra. The output power is $31.9 / 30.6 \mathrm{dBm}$ in the two bands. When digital predistortion (DPD) is on, the adjacent channel power ratio (ACPR) is $-47.0 /-48.1 \mathrm{dBc}$, respectively. The DPD used a generalized memory polynomial model based on a negative feedback iteration technique.
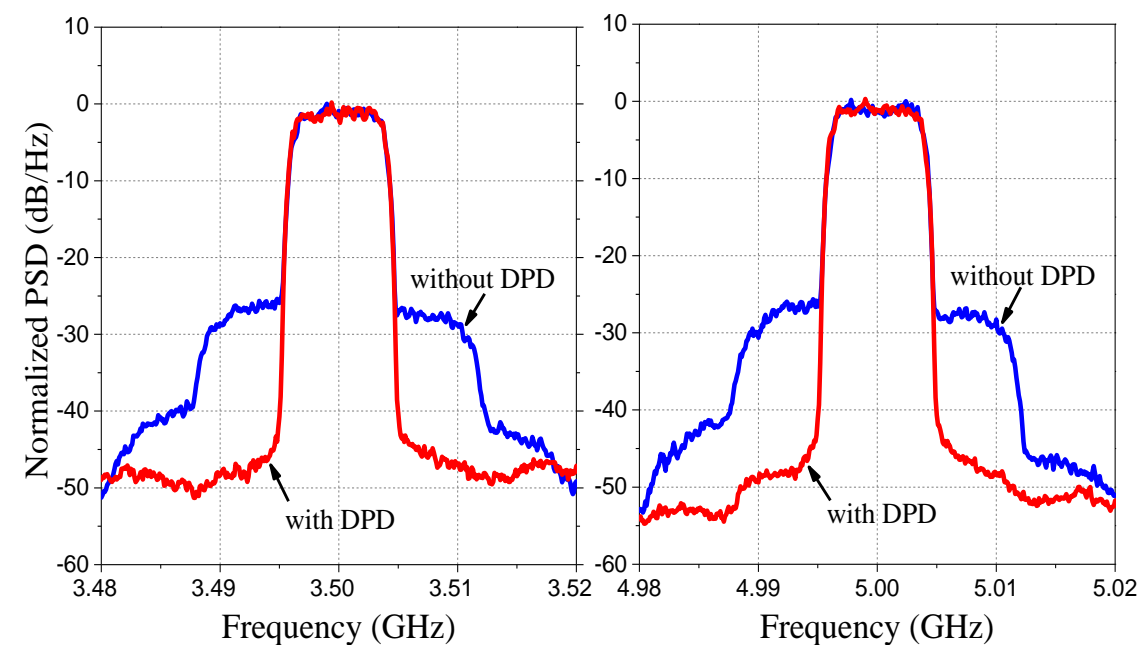

Figure 12. Normalized output spectra of the fabricated PA under 10-MHz 6.6-dB PAPR WCDMA signal excitation, before and after DPD linearization. 
Table 1 displays the results of this work together with other recent studies of dualband PAs. Due to the nature of the unique dual-output architecture and the high operation frequencies, the PA proposed in this study cannot be directly compared to other singleoutput works [3,7,18-21]. Nevertheless, the dual-output PAs have a wider noncontiguous absolute bandwidth $(2.0$ and $1.5 \mathrm{GHz})$ than the single-output PAs, and the high working frequencies are closer to the widely used sub-6 GHz 5G bands that will predominate in future wireless communications. Compared to the previous work in dual-band, dualoutput PAs, this PA has better efficiencies and gain at the two operating frequencies, closer to the normal dual-band PA. Moreover, the simple structure and the generalized design methodology will make the PA extensible, easier to design, and have more potential for practical uses.

Table 1. Performance comparison of dual-band PAs.

\begin{tabular}{|c|c|c|c|c|c|c|c|}
\hline Ref. & Year & Freq. & Architecture & No. of Loads & $\begin{array}{l}\text { Output } \\
\text { Power }\end{array}$ & Gain & Efficiency \\
\hline [3] & 2020 & $2.1 / 3.45$ & Doherty & 1 & $48 / 47.5$ & $8.4 / 9.2$ & DE:72/63 \\
\hline [7] & 2018 & $1.4 / 2.4$ & $\begin{array}{l}\text { Single-ended } \\
\text { Single-output }\end{array}$ & 1 & $41 / 40$ & $13 / 12.5$ & PAE:65/67 \\
\hline [18] & 2018 & $1.8 / 2.65$ & $\begin{array}{l}\text { Single-ended } \\
\text { Single-output }\end{array}$ & 1 & $43 / 42.7$ & $12.9 / 11.0$ & DE:76.2/71.6 \\
\hline [20] & 2012 & $1.8 / 2.4$ & Doherty & 1 & $43 / 43$ & $12 / 13$ & PAE:64/54 \\
\hline [21] & 2019 & $0.85 / 2.0$ & Doherty & 1 & $44.6 / 44.2$ & $8.3 / 10$ & DE:58/68 \\
\hline [16] & 2019 & $3.5 / 5.5$ & $\begin{array}{l}\text { Single-ended } \\
\text { Dual-output }\end{array}$ & 2 & $36.7 / 37.1$ & $11.4 / 9.0$ & PAE:40.4/39.9 \\
\hline This study & 2021 & $3.5 / 5.0$ & $\begin{array}{c}\text { Single-ended } \\
\text { Dual-output }\end{array}$ & 2 & $40.2 / 40.7$ & $11.6 / 9.8$ & $\begin{array}{l}\text { DE: } 55.8 / 53.8 \\
\text { PAE:47.7/45.4 }\end{array}$ \\
\hline
\end{tabular}

\section{Conclusions}

A dual-band, dual-output power amplifier designed with a simplified three-port, frequency-dividing matching network was presented in this study. The OMN with two branches could send signals in different bands into different output ports using restraining networks that prevented unwanted signals from passing through. In each branch, secondorder harmonics were controlled for better efficiency. The PA with a 10-W CGH40010F packaged GaN HEMT achieved a DE of $55.84 \% / 53.68 \%$ and output power of $40.22 / 40.77 \mathrm{dBm}$ at $3.5 / 5.0 \mathrm{GHz}$. It can be expected that the high performance, simple structure, and generalized design methodology will make this PA extensible and have more potential for practical uses.

\section{Patents}

The corresponding Chinese patent (no. 202010299317.5) of this work has already been granted.

Author Contributions: Conceptualization, Y.W. and X.C.; methodology, X.C.; software, X.C.; validation, X.C., Y.W., and W.W.; formal analysis, X.C. and Y.W.; investigation, Y.W.; resources, Y.W. and W.W.; data curation, X.C.; writing-original draft preparation, X.C.; writing-review and editing, Y.W. and W.W.; visualization, X.C.; supervision, Y.W. and W.W.; project administration, W.W.; funding acquisition, Y.W. and W.W. All authors have read and agreed to the published version of the manuscript.

Funding: This research was supported by National Natural Science Foundations of China (No.61971052, U21A20510, and No. U20A20203) and the Fundamental Research Funds for the Central Universities (2021XD-A07-1).

Data Availability Statement: The data presented in this study are available within the article. 
Conflicts of Interest: The authors declare no conflict of interest.

\section{References}

1. Yin, Y.; Xiong, L.; Zhu, Y.; Chen, B.; Min, H.; Xu, H. A compact dual-band digital polar Doherty power amplifier using parallel-combining transformer. IEEE J. Solid-State Circuits 2019, 54, 1575-1585. [CrossRef]

2. Park, J.; Lee, C.; Park, C. A quad-band CMOS linear power amplifier for EDGE applications using an anti-phase method to enhance its linearity. IEEE Trans. Circuits Syst. I Regul. Papers 2017, 64, 765-776. [CrossRef]

3. Liu, M.; Fang, X.; Huang, H.; Boumaiza, S. Dual-band 3-way Doherty power amplifier with extended back-off power and bandwidth. IEEE Trans. Circuits Syst. II Express Briefs 2020, 67, 270-274. [CrossRef]

4. Liu, H.-Y.; Zhai, C.; Cheng, K.-K.M. Novel dual-band equal-cell Doherty amplifier design with extended power back-off range. IEEE Trans. Microw. Theory Tech. 2020, 68, 1012-1021. [CrossRef]

5. Yang, Z.; Li, M.; Yao, Y.; Dai, Z.; Li, T.; Jin, Y. Design of concurrent dual-band continuous Class-J mode Doherty power amplifier with precise impedance terminations. IEEE Microw. Wirel. Compon. Lett. 2019, 29, 348-350. [CrossRef]

6. Dai, Z.; Pang, J.; Li, M.; Li, Q.; Peng, J.; He, S. A Direct Solving Approach for High-Order Power Amplifier Matching Network Design. IEEE Trans. Microw. Theory Tech. 2020, 68, 3278-3286. [CrossRef]

7. Meng, X.; Yu, C.; Wu, Y.; Liu, Y. Design of dual-band high-efficiency power amplifiers based on compact broadband matching networks. IEEE Microw. Wirel. Compon. Lett. 2018, 28, 162-164. [CrossRef]

8. Zhuang, Z.; Wu, Y.; Yang, Q.; Kong, M.; Wang, W. Broadband power amplifier based on a generalized step-impedance quasichebyshev lowpass matching approach. IEEE Trans. Plasma Sci. 2020, 48, 311-318. [CrossRef]

9. Krishnamoorthy, R.; Kumar, N.; Grebennikov, A.; Ramiah, H. A high-efficiency ultra-broadband mixed-mode GaN HEMT power amplifier. IEEE Trans. Circuits Syst. II Express Briefs 2018, 65, 1929-1933. [CrossRef]

10. Chen, H.; Xu, J.-X.; Kong, Z.-H.; Chen, W.-H.; Zhang, X.Y. Broadband High-Efficiency Power Amplifier With Quasi-Elliptic Low-Pass Response. IEEE Access 2020, 8, 52566-52574. [CrossRef]

11. Saxena, S.; Rawat, K.; Roblin, P. Continuous class-B/J power amplifier using a nonlinear embedding technique. IEEE Trans. Circuits Syst. II Express Briefs 2017, 64, 837-841. [CrossRef]

12. Ghisotti, S.; Pisa, S.; Colantonio, P. S Band Hybrid Power Amplifier in GaN Technology with Input/Output Multi Harmonic Tuned Terminations. Electronics 2021, 10, 2318. [CrossRef]

13. Azam, A.; Bai, Z.; Walling, J.S. Leveraging programmable capacitor arrays for frequency-tunable digital power amplifiers. IEEE Trans. Microw. Theory Tech. 2020, 68, 1983-1994. [CrossRef]

14. Choi, J.; Hwang, W.; You, C.; Jung, B.; Hong, W. Four-element reconfigurable coupled loop MIMO antenna featuring LTE full-band operation for metallic-rimmed smartphone. IEEE Trans. Antennas Propag. 2019, 67, 99-107. [CrossRef]

15. Zou, H.; Li, Y.; Shen, H.; Wang, H.; Yang, G. Design of $6 \times 6$ dual-band MIMO antenna array for 4.5 G/5G smartphone applications. In Proceedings of the 2017 Sixth Asia-Pacific Conference on Antennas and Propagation (APCAP), Xi'an, China, 16-19 October 2017; pp. 1-3.

16. Cappello, T.; Duh, A.; Barton, T.W.; Popovic, Z. A dual-band dual-output power amplifier for carrier aggregation. IEEE Trans. Microw. Theory Tech. 2019, 67, 3134-3146. [CrossRef]

17. Duh, A.; Rahimizadeh, S.; Barton, T.; Popović, Z. A 3.5/5.9-GHz dual-band output matching network for an efficiency-optimized multiband power amplifier. In Proceedings of the 2018 IEEE Topical Conference on RF/Microwave Power Amplifiers for Radio and Wireless Applications (PAWR), Anaheim, CA, USA, 14-17 January 2018; pp. 75-78.

18. Huang, H.; Zhang, B.; Yu, C.; Gao, J.; Wu, Y.; Liu, Y. A novel analytic design method of dual-band harmonic-tuned power amplifiers. Microw. Opt. Technol. Lett. 2018, 60, 2496-2500. [CrossRef]

19. Chen, W.; Zhang, S.; Liu, Y.; Liu, Y.; Ghannouchi, F.M. A concurrent dual-band uneven Doherty power amplifier with frequencydependent input power division. IEEE Trans. Circuits Syst. I Regul. Papers 2014, 61, 552-561. [CrossRef]

20. Saad, P.; Colantonio, P.; Piazzon, L.; Giannini, F.; Andersson, K.; Fager, C. Design of a concurrent dual-band 1.8-2.4-GHz GaN-HEMT Doherty power amplifier. IEEE Trans. Microw. Theory Tech. 2012, 60, 1840-1849. [CrossRef]

21. Kalyan, R.; Rawat, K.; Koul, S.K. A digitally assisted dual-input dual-band Doherty power amplifier with enhanced efficiency and linearity. IEEE Trans. Circuits Syst. II Express Briefs 2019, 66, 297-301. [CrossRef] 